\title{
INTERFERENSI BAHASA INDONESIA KE DALAM BAHASA SUNDA DALAM ABSTRAK SKRIPSI (Kajian Morfologis dan Leksikosemantis)
}

\author{
Tintin Supriatin \\ SMPN 1 Pasawahan Kabupaten Purwakarta \\ Pos-el: tienspurwakarta@gmail.com
}

\begin{abstract}
Abstrak
Penelitian ini dilatarbelakangi oleh adanya kesalahan penggunaan kata yang tidak sesuai dengan tata bentuk atau morfologi serta tidak sesuai pula dengan konteks pemakaiannya atau disebut juga interferensi leksikosemantis. Adapun tujuan dari penelitian ini yaitu untuk mengetahui dan mendeskripsikan kesalahan morfologis dan leksikosemantik yang dilakukan oleh mahasiswa FISIP UNPAS, yang meliputi (1) interferensi bentuk kata (morfologis), (2) interferensi leksikosematis, dan (3) distribusi frekuensi interferensi. Metode yang digunakan dalam penelitian ini yaitu metode deskriptif, sedangkan tehnik yang digunakan untuk pengumpulan serta pengolahan data yaitu tehnik tes dan tehnik analisis data. Sumber data dalam penelitian ini yaitu abstrak skripsi mahasiswa FISIP UNPAS, sedangkan data dalam penelitian ini adalah data interferensi morfologis dan leksikosemantis yang terdapat dalam abstrak mahasiswa. Hasil penelitian ini adalah (1) interferensi morfologis $138 \mathrm{kata}(21,61 \%)$, dengan rincian (a) afiksasi 93 kata (14,61\%), (b) komposisi jumlahnya 42 kata (6,53\%), (c) reduplikasi 2 kata $(0,31 \%)$, dan akronim hanya satu kata (0,15\%): (2) interferensi leksikosemantis sebanyak 505 kata $(78,39 \%)$, dengan rincian (a) murni sebanyak 225 kata $(34,99 \%$ ) dan (b) kesalahan serapan sebanyak 101 kata (15,52\%); serta rekaan sebanyak 179 kata (27,83\%). Berdasarkan hasil tersebut, dapat disimpulkan bahwa mahasiswa masih melakukan interferensi morfologis dan leksikosemantis.
\end{abstract}

Kata kunci: interferensi, morfologis, leksikosemantis, abstrak

\section{INDONESIAN INTERFERENCE IN SUNDANESE RESEARCH PAPER'S ABSTRACTS (A Morphological and Lexicosemantic Study)}

\begin{abstract}
This study was motivated by the phenomenon of incorrect use of words in terms of their morphology and contexts of use or also known as lexicosemantic interference. The goal of the study is to discover and describe the morphologicaland lexicosemantic mistakes by students of FISIP UNPAS, which include (1) word formation interference (morphology), (2) lexicosemantic interference, and (3) distribution of the frequency of interference. The method used is a decriptive method and data processing technique is immediate constituent analysis. Data came from abstracts of research paper of students of FISIP UNPAS.Results indicate (1) there are 138 words of morphology interference, consisting of (a) 93 data of affixation with 8 patterns and 27 subpatterns, (b) 42 data of composition, (c) 2 words of reduplication and 1 word of acronym; (2) 505 words of lexicosemantic interference with the following details: (a) pure (225 data), (b) loanword (101 data), and made up (179 data with 3 patterns). Based on the result above, it can be concluded that there is morphologicaland lexicosemantic interference in the students' abstracts.
\end{abstract}

Keywords: interference, morphology, lexicosemantic, abstract 


\section{PENDAHULUAN}

Sifat fleksibel yang dimiliki oleh suatu bahasa menyebabkan bahasa selalu mengalami perubahan dan perkembangan. Perubahan dan perkembangan ini sesuai dengan situasi, kondisi serta keperluan penuturnya. Berubahnya keadaan sosial, ekonomi, budaya serta kontak dalam bidang politik, teknologi, ilmu pengetahuan dan berbagai hal lainnya menyebabkan proses saling mempengaruhi antarbahasa tidak dapat dihindarkan. Bahasa selaku bagian integral dari kebudayaan tidak dapat lepas dari berbagai masalah. Kontak bahasa akan berlangsung dalam berbagai aspek tataran kebahasaan. Proses transfer atau pindahnya unsur suatu bahasa ke bahasa lain atau proses saling pinjam unsur bahasa merupakan hal yang biasa. Suwito (1985: 35-40) menjelaskan bahwa seorang penutur menggunakan dua bahasa atau lebih secara bergantian dapat disebutkan bahwa bahasa saling mempengaruhi antara satu bahasa dengan bahasa lain berlangsung. Akibatnya interferensi akan muncul dalam bentuk lisan atau tulisan.

Masyarakat bahasa yang tinggal terpencil, yang tidak berinteraksi dengan masyarakat lainnya dapat tertinggal dan tetap jadi masarakat ekabahasa (monolingual). Sebaliknya, masyarakat bahasa yang terbuka, artinya, yang memiliki hubungan dengan masyarakat lain, pasti akan mengalami kontak bahasa yang dalam sosiolinguistik akan mengakibatkan yang disebut bilingualisme, diglosia, alih kode, campurkode, interferensi, integrasi, konvergensi, dan pergseran bahasa (Chaer \& Agustina, 2010: 84). Masyarakat Sunda termasuk masyarkat terbuka, selaku penutur bahasa daerah terbanyak kedua di Indonesia setelah bahasa Jawa yang tinggal di wilayah Provinsi Jawa Barat, Banten, juga Cirebon, baik yang bertempat tinggal di pedesaan ataupun di perkotaan, memiliki kemampuan untuk menguasai bahasa lain, sehingga bahasa Sunda mengalami kontak bahasa dengan bahasa lainnya.
Pemerolehan bahasa didapat melalui proses interaksi dalam kehidupan seharihari serta melalui proses belajar, baik bahasa pertama maupun kedua. Mahasiswa selaku masyarakat terdidik termasuk penutur bilingual bahkan bisa jadi multilingual, yang dapat menggunakan bahasa secara bergantian antara bahasa yang dikuasainya. Hal ini menyebabkan interferensi yang terdapat dalam proses komunikasi, baik komunikasi lisan maupun tulis, baik resmi maupun tidak.

Bahasa Sunda sebagai bahasa ibu (mother tongue) di wilayah Jawa Barat, sekarang sudah dipakai di berbagai aspek kegiatan. Bukan hanya digunakan dalam komunikasi lisan tetapi juga digunakan dalam komunikasi tulis baik dalam situasi resmi maupun situasi tidak resmi. Di samping itu, bahasa Sunda juga dipakai dalam kegiatan ilmiah, seperti pada orasi ilmiah penganugerahan Dr. (HC) untuk Ajip Rosidi pada Sidang Senat Universitas Padjadjaran, skripsi mahasiswa program studi Pendidikan Bahasa Daerah FPBS UPI, Tesis mahasiswa Program Studi Pendidikan Bahasa dan Budaya Sunda Sekolah Pascasarjana UPI, serta Abstrak Skripsi mahasiswa di Universitas Pasundan.

Universitas Pasundan merupakan salah satu perguruan tinggi yang terbilang tua dan potensial di wilayah Jawa Barat.Universitas ini memiliki enam fakultas, yaitu Fakultas Hukum, Fakultas Ilmu Sosial dan Ilmu Politik, Fakultas Ilmu Seni dan Sastra, Fakultas Ekonomi, dan Fakultas Keguruan dan Ilmu Pendidikan dan Fakultas Tekhnik. Dalam salah satu kebijakannya menyebutkan bahwa abstrak skripsi mahasiswa UNPAS ditulis dalam tiga bahasa, yaitu dalam bahasa Indonesia, bahasa Inggris, dan bahasa Sunda, meskipun dalam implementasinya baru pada Fakultas Ilmu Sosial dan Ilmu Politik.

Dalam abstrak skripsi bahasa Sunda mahasiswa FISIP UNPAS ditemukan banyaknya kelemahan-kelemahan di antaranya kesalahan dalam proses pembentukkan kata (morfologis), serta 
kesalahan dalam menggunakan dan menerjemahkan kata yang tidak sesuai dengan konteksnya (leksikosemantis), dalam hal ini banyak interferensi dari bahasa Indonesia ke dalam basa Sunda. Hal ini diakibatkan di antaranya oleh proses menerjemahkan abstrak bahasa Indonesia ke dalam bahasa Sunda secara tekstual (kata per kata). Latar belakang mahasiswa yang multikultural juga berpengaruh kedalam proses menerjemahkan abstrak skripsi dari bahasa Indonesia ke dalam bahasa Sunda. Oleh sebab itu, penelitian ini dianggap penting untuk mengetahui sampai sejauh mana interferensi morfologis dan leksikosemantis dalam abstrak skripsi mahasiswa FISIP UNPAS.

Menurut Pateda (2010: 81), interferensi merupakan saling mempengaruhi bahasa. Biasanya antara bahasa yang berdekatan dan hidup di masyarakatnya. Rusyana (dalam Huda dkk., 1981: 52) memberikan pendapat bahwa interferensi berlangsung karena adanya kecenderungan pada dwibahasawan untuk menyamakan unsur-unsur yang ada dalam bahasa lain ketika adanya kontak dua bahasa. Tarigan \& Tarigan (2011: 16) menyebutkan bahwa saling mempengaruhi antara bahasa pertama dengan bahasa kedua dalam unsur fonologi, morfologi atau sintaksis lantaran adanya kontak bahasa dalam diri dwibahasawan. Pemakaian sistem bahasa tertentu terhadap bahasa lainnya disebut transfer. Seumpama sistem yang digunakeun itu bersamaan, maka transfer tersebut termasuk positif. Sebaliknya, bila sistem yang digunakan menyimpang atau berlawanan, maka transfer itu disebut negatif. Transfer negatif mengakibatkan kelemahan dalam pengajaran bahasa kedua dan sekaligus menjadi salah satu sumber kesalahan berbahasa. Transfer negatif lebih dikenal dengan istilah interferensi. Interferensi bisa diartikan sebagai pemakaian sistem bahasa pertama dalam menggunakan bahasa kedua, sedangkan sistem tersebut tidak sama dalam kedua bahasa tersebut.

Hartman \& Stork (dalam Alwasilah,
1993: 16) menyebutkan interferensi sebagai kekeliruan yang disebabkan terbawanya kebiasaan-kebiasaan ujaran bahasa atau dialek ibu ke dalam bahasa atau dialek kedua. Oleh sebab itu, menurut Alwasilah interferensi bisa berlangsung tidak sebatas hanya pada tata bahasa dan kosa kata, tetapi bisa juga dalam arti budada baik dalam ragam lisan maupun dalam ragam tulisan.Interferensi sifatnya individual, jadi idiosinkrasi dan parole penutur.

Adapun istilah leksikal, Parera (1997: 86) menyebutkan bahwa leksikal itu berupa kumpulan kata-kata dan idiom suatu bahasa; ada beberapa macam sesuai dengan bidang pemakaian kata-kata dengan idiom itu sendiri.

Kridalaksana (1994: 18) memberi definisi unsur leksikal yaitu: (1) Komponen bahasa yang memuat semua informasi tentang makna dan pemakaian kata dalam bahasa; (2) kekadaan kata yang dimiliki seorang pembicara, penulis, atau suatu bahasa, kosa kata, pembendaharaan kata; (3) daftar kata yang disusun seperti kamus, tetapi dengan penjelasan yang singkat dan praktis. Sudaryat (2007:55) menyimpulkan bahwa leksikal yaitu macam-macam hubungan makna yang ada dalam kata atau kosa kata.

Interferensi yang berlangsung dalam bidang morfologi dan sintaksis biasa disebut inteferensi gramatikal. Interferensi gramatikal tersebut mengacu pada bentuk morfologis. Bentuk morfologis meliputi proses afiksasi, reduplikasi, komposisi, dan abreviasi.

Interferensi leksikal mengacu pada bentuk leksem berikut maknannya, seperti relasi semantis (sinonim dan homonim berikut menilik bentuk murni BI, serapan atau rekaan).

\section{METODE}

Metode yang digunakan dalam penelitian ini ialah metode deskriptif. Hal ini dilakukan untuk mengumpulkan informasi faktual secara terperinci dan 
menggambarkan hal-hal yang menjadi pusat perhatian dalam objek tulisan. Metode ini dilengkapi oleh kegiatan proses analisis agar mendapat pembahasan yang lengkap tentang interferensi dalam abstrak skripsi dari beberapa sumber data yang selanjutnya dianalisis. Yang dideskripsikannya ialah mengenai interferensi leksikosemantis dan morfologis dalam abstrak skripsi mahasiswa. Interferensi leksiko-gramatikal yang dibahas meliputi interferensi leksikal dari BI terhadap BS dan Interferensi bentuk kata (berafiks, reduplikasi, komposisi, dan abreviasi) dari BI terhadap BS.

Data dalam tulisan ini ialah abstrak skripsi mahasiswa FISIP UNPAS yang meliputi Jurusan Ilmu Adminstrasi Negara, Kesejahteraan Masyarakat, Hubungan Internasional, Administrasi Bisnis jeung Ilmu Komunikasi, yang mengandung gejala interferensi. Untuk Jurusan Kesejahteraan Masyarakat tidak ditemukan adanya abstrak skripsi dalam bahasa Sunda. Sampel penelitian ini hanya meliputi empat jurusan yang dipilih sacara acak dari jurusan-jurusan di atas mulai tahun 2007 sampai dengan 2013. Dari sampel sampel tersebut dipilih 40 abstrak yang representatif, dengan teknik memilih sampel secara purposif.

Instrumen yang digunakan dalam tulisan ini ialah sistem kartu data dan sistem tabel atau sistem tabulasi. Kartu data dalam tulisan ini berfungsi untuk mengumpulkan data tulisan. Tujuannya agar memudahkan dalam menganalisis data serta mudah untuk membuat kesimpulan. Adapun tabulasi data merupakan teknik untuk memilah-milah data yang disusun dalam bentuk tabel. Format tabulasi data yang digunakan dalam tulisan ini ialah tabel seluruh data yang termasuk ke dalam interferensi, yang selanjutnya diklasifikasikan dalam tabel interferensi bentuk leksikosemantis dan interferensi bentuk morfologis.

\section{HASIL DAN PEMBAHASAN}

Data dalam penelitian ini adalah abstrak skripsi yang berjumlah 40. Data yang dibahas adalah data yang memiliki interferensi dari BI ke dalam BS, baik leksikosemantis maupun morfologis. Data yang memiliki unsur interferensi, berjumlah 643, dengan perincian interferensi morfologis berjumlah 138 data, sedangkan interferensi leksikosemantis sebanyak 505 data.

Dalam penelitian ini dibahas mengenai interferensi bahasa Indonesia (BI) ke dalam bahasa Sunda. Oleh sebab itu, sebagai bahan perbandingan akan dibahas dahulu proses morfologis dalam bahasa Indonesia sebagaimana dijelaskan oleh Kridalaksana (1994:12) sekurang-kurangnya ada tujuh proses morfologis, di antaranya: (1) derivasi zero, (2) afiksasi, (3) reduplikasi, (4) abreviasi, (5) komposisi, (6) derivasi balik, dan (7) metanalisis.

Peristiwa morfologis berlangsung dari input, yaitu leksem dan salah satu proses yang disebutkan di atasa serta output yaitu kata. sebagaimana tergambar dalam bagan di bawah ini.

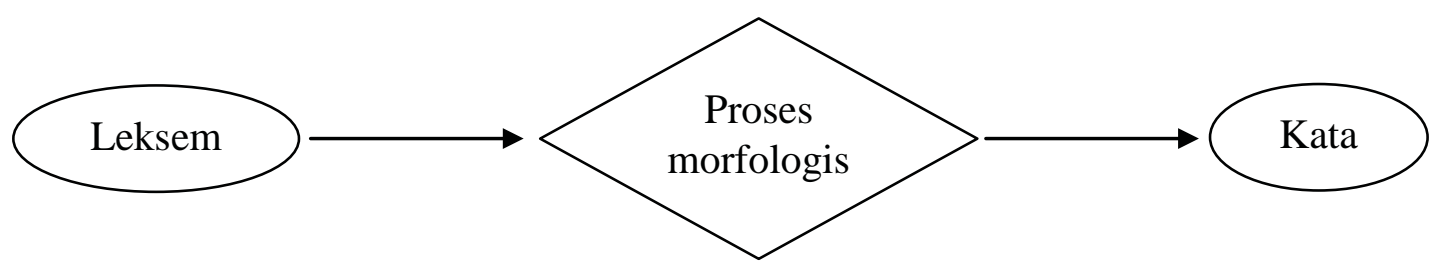

Bagan 1: Peristiwa Morfologis 


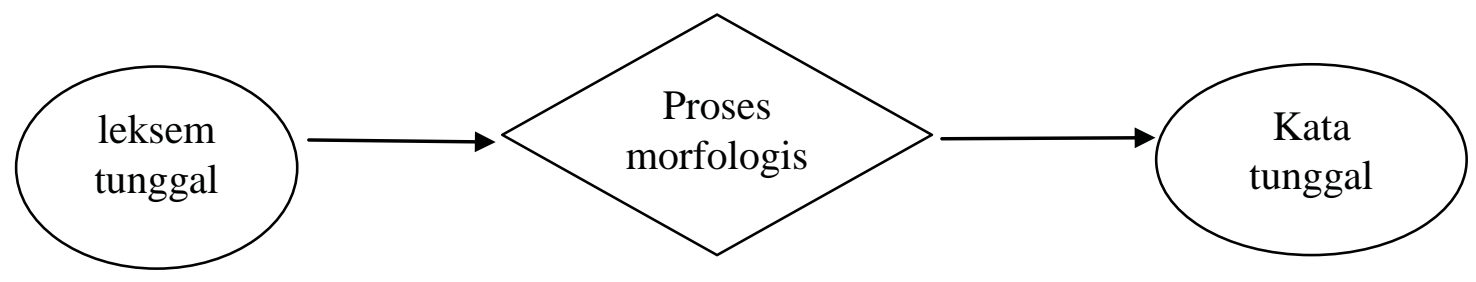

Bagan 2: Derivasi Zero

(1) derivasi zero, dalam proses ini leksem menjadi kata tungggal yang tidak merubah apapun.

(2) afiksasi: dalam proses ini leksem berubah menjadi kata yang kompleks.

(3) reduplikasi: dalam proses ini leksem berubah menjadi kata yang kompleks dengan beberapa proses pengulangan lagi.

(4) abreviasi: dalam proses ini leksem atau gabungan leksem berubah menjadi kata yang kompleks atau akronim/singkatan dengan beberapa proses abreviasi. Ada beberapa jenis abreviasi:
(a) pemenggalan,
(b) kontraksi,
(c) akronimi, jeung
(d) menyingkat.

Dalam pemenggalan dan kontraksi inputnya yaitu leksem tunggal dan outputnya kata kompleks seperti yang terdapat dalam afiksasi dan reduplikasi sebagaimana tergambar dalam bagan di bawah ini. leksem

tunggal

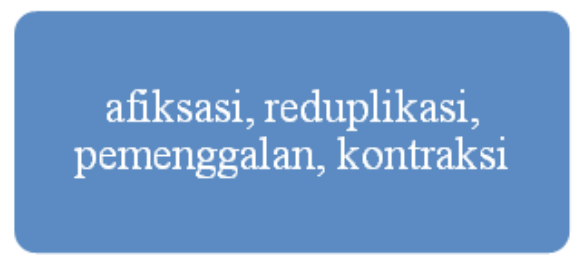

Bagan 3: Leksem Tunggal
Akronim dan menyingkat inputnya dua leksem atau lebih serta outputnya akronim atau singkatan, sebagaimana tergambar dalam bagan di bawah ini.

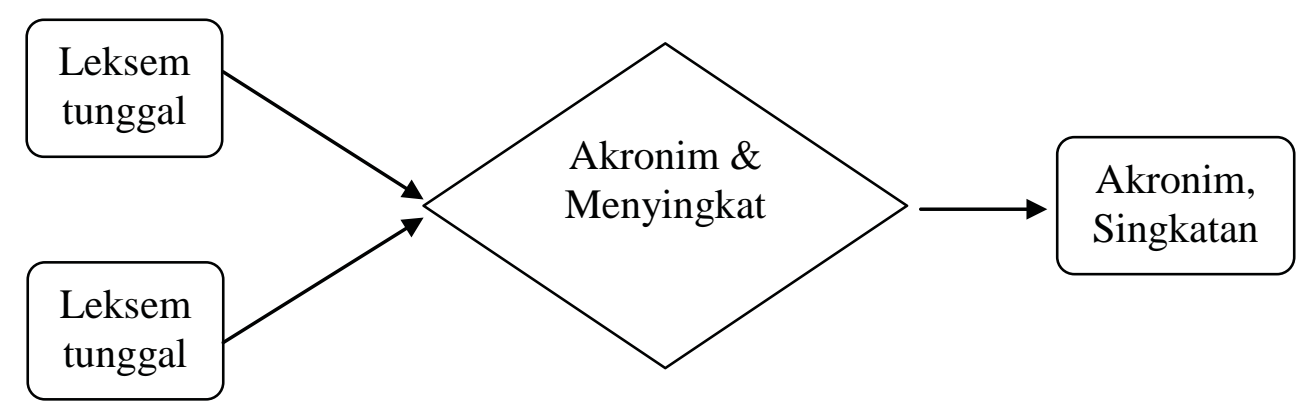

Bagan 4: Akronim 
Singkatan akronim secara gramatikal statusnya adalah kata.
(5) kompositum dalam tingkat morfologi atau kata majemuk dalam tingkat sintaksis, sebagaimana tergambar dalam bagan di bawah ini.

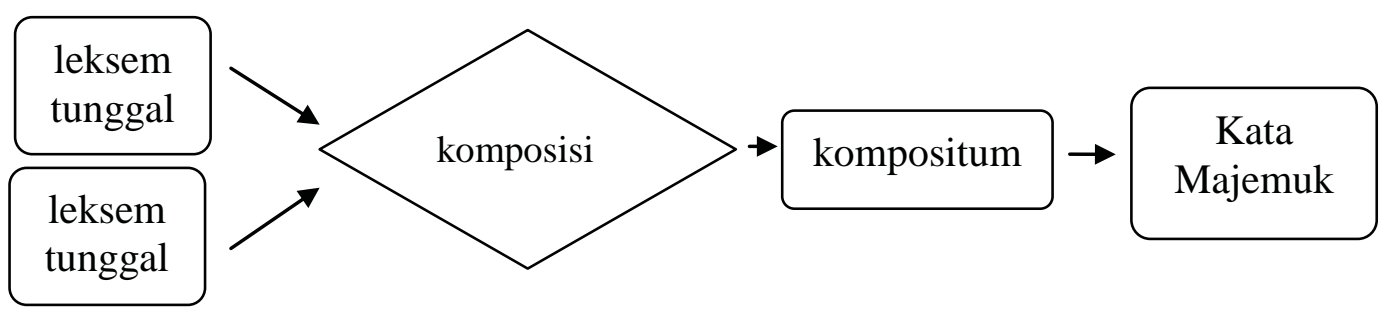

\section{Bagan 5: Kata Majemuk}

(6) derivasi terbalik, dalam proses ini inputnya leksem tunggal, serta outputnya kata kompleks yang prosesnya berlangsung seperti afiksasi.
Kata majemuk yang dihasilkan oleh proses komposis yang bersifat morfologis ternyata berbeda sifatnya dengan frasa yang berupa gabungan kata yang sifatnya sintaksis. Berlangsungnya frasa bisa digambarkan dalam bagan di bawah ini.

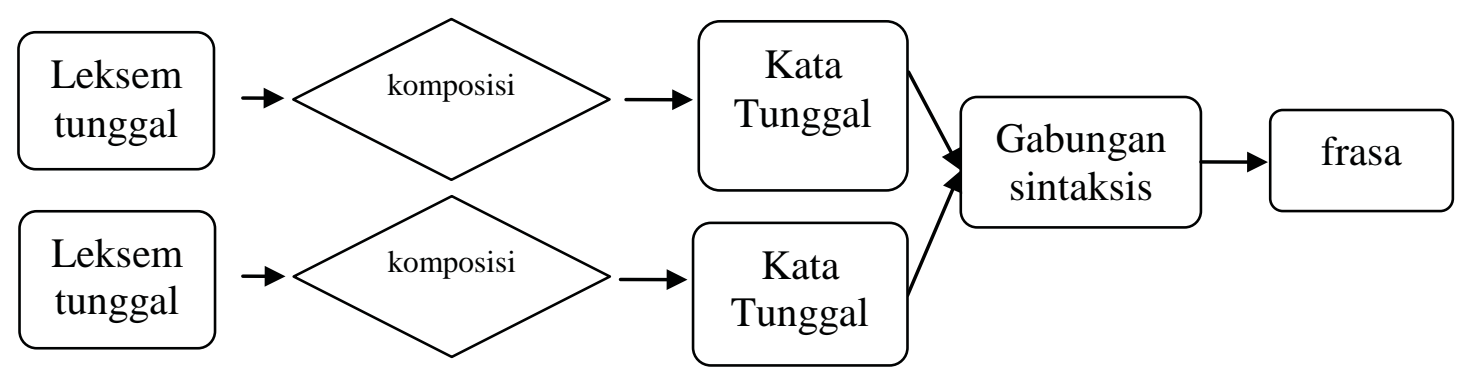

Bagan 6: Frasa

Pembentukan kata dalam BI sipatnya rekursif, satu leksem atau setelah mengalami proses morfologis manjadi kata dan unsur ini mengalami proses morfologis lagi dan menjadi kata baru. Berubahnya leksem menjadi kata disebut gramatikalisasi, dan mengembalikan lagi kata menjadi unsure leksikal disebutna leksikalisasi.

\section{Analisis Interferensi Morfologis}

Interferensi morfologis merupakan pengaruh menggunakan bentuk kata suatu bahasa kepada bahasa lain, dalam hal ini BI ke dalam BS.
Berdasarkan hasil analisis data interferensi morfologis BI ke dalam BS dalam abstrak skripsi mahasiswa terdiri atas empat bentuk (1) afiksasi, (2) komposisi, (3) reduplikasi, dan (4) abreviasi.
Afiksasi
Interferensi morfologis afiksasi merupakan interferensi dari BI ke dalam BS. Hasil analisis data ditemukan 93 interferensi morfologis. Setelah dianalisis dapat digolongkan menjadi 8 pola, saperti pada tabel berikkut 
Tabel 1: Pola Interferensi Morfologis afiksasi

\begin{tabular}{|c|c|c|c|c|}
\hline No. & Pola & Uraian & Imbuhan & Jumlah Data \\
\hline \multirow[t]{5}{*}{1.} & 1 & Préf BS + BD BI & ka- + BD BI & 2 \\
\hline & & & di-+ BD BI & 1 \\
\hline & & & $\mathrm{N}-+$ BD BI & 15 \\
\hline & & & pa- + BD BI & 1 \\
\hline & & & sa- + BD BI & 2 \\
\hline 2 & 2 & $\mathrm{BD} B \mathrm{BI}+\inf \mathrm{BS}$ & -in- + BD BI & 1 \\
\hline \multirow[t]{2}{*}{3.} & 3 & $\mathrm{BD} B I+\operatorname{suf} \mathrm{BS}$ & BD BI + -na & 12 \\
\hline & & & BD BI + -keun & 2 \\
\hline \multirow[t]{8}{*}{4.} & 4 & $\mathrm{BD} \mathrm{BI}+$ konf BS & di- + BD BI + -keun & 4 \\
\hline & & & di- + BD BI + -na & 1 \\
\hline & & & $\mathrm{N}-+$-um- + BD BI & 1 \\
\hline & & & $\mathrm{N}-+$ BD BI + -keun & 14 \\
\hline & & & pa- + BD BI + -an & 8 \\
\hline & & & sa- + BD BI + -na & 1 \\
\hline & & & ka- + BD BI + -an & 3 \\
\hline & & & $\mathrm{N}-+\mathrm{BD} \mathrm{BI}+-\mathrm{i}$ & 2 \\
\hline \multirow[t]{3}{*}{5} & 5 & $\mathrm{BD} B S+\operatorname{suf} \mathrm{BI}$ & $\mathrm{BD} \mathrm{BS}+$-is & 1 \\
\hline & & & BD BS + -isme & 1 \\
\hline & & & BD BS + -pun & 1 \\
\hline 6. & 6 & BD BS + konf BI & per- +BD BS+ -an & 2 \\
\hline \multirow[t]{4}{*}{7.} & 7 & Pola Campuran & $\mathrm{N}-+\mathrm{BD} B \mathrm{BK}$ & 1 \\
\hline & & & me- + N- + BD BI + -keun & 3 \\
\hline & & & di- + per- + BD BI + -keun & 3 \\
\hline & & & ter- + BD BI + -na & 2 \\
\hline \multirow[t]{4}{*}{8.} & 8 & Pola Unik & pang- + BD BS (tak lazim) & 1 \\
\hline & & & Ka-+ BD BS (tak lazim) & 2 \\
\hline & & & N- BD BS (tak lazim) & 4 \\
\hline & \multicolumn{3}{|c|}{ Jumlah } & 93 \\
\hline
\end{tabular}

Berdasarkan bentuk afiksasi terdapat 26 subpola interferensi afiksasi yang berjumlah 94 data kata berimbuhan.Yang menjadi kajiannya yaitu bentuk dasar (BD) BS diberikan imbuhan BI atau yang menyerupai BI. Meskipun terdapat juga BD dalam BI yang diberikan imbuhan oleh BS. Dari 27 subpola yang diberikan imbuhan dalam BI mempengaruhi ke dalam imbuhan BS. Imbuhan tersebut awalan (prefiks), sisipan (infiks), akhiran (sufiks), dan imbuhan gabung (konfiks). Analisis diuraikan berikut data interferensi (DI), afiksasi BI (IBI), seharusnya dalam BS dan pola afiksasinya, sebagai contoh berikut disajikan beberapa analisis data. a. Pola 1a: Interferensi Morfologis $k a-+B D B$ Pola 1a merupakan interferensi morfologis awalan (prefiks) ka- yang BDnya dari BI.

$$
\begin{gathered}
\text { (064) kacapai }(\mathrm{DI}) \rightarrow \text { leksem capai }+ \text { ka- }(\text { pref BS }) \\
\downarrow \\
\text { kahontal }(\mathrm{BS})
\end{gathered}
$$

Kata jadian kacapai terdapat dalam abstrak terdapat satu kali. Bila dilihat dari penggunakan kata kacapai berasal dari kata dasar BI yaitu capai $=$ BD capai + prefix $k a-$. Dalam konteks kalimat maksudnya mengandung arti kahontal dalam BS. Jika dalam struktur BI bisa jadi bermakna 
sama dengan maksud kalimatnya. Tapi jika dalam BS memiliki makna yang salah. Dengan demikian kata yang sesuai untuk menggambarkan makna kacapai adalah kata kahontal. Kata lain yang memiliki pola yang sama adalah (146) kabuka. Dua kata ini termasuk interferensi morfologis.

\section{Interferensi Morfologis Komposisi}

Interferensi mrfologis komposisi berdasarkan pengaruh satu bahasa ke bahasa lain, dalam hal ini BI ke dalam BS, pada aspek komposisi. Data interferensi dari unsur morfologis aspek kata majemuk atau proses komposisi dalam abstrak berjumlah 42 kata.

Setelah dianalisis berdasarkan bentuk kata dapat digolongkan menjadi 13 pola, saperti pada tabel berikut.

\section{Tabel 2: Pola Interferensi Morfologis}

\begin{tabular}{cclc}
\hline No. & Pola & \multicolumn{1}{c}{ Uraian } & Jumlah Data \\
\hline 1. & 1. & BD BI + BD BI & 9 \\
\hline 2. & 2 & BD BI + BD BS & 5 \\
\hline 3. & 3 & BT BI + BD BS & 7 \\
\hline 4. & 4 & BD BS + BD BS & 4 \\
\hline 5. & 5 & BT BS + BD BS & 1 \\
\hline 6. & 6 & BT BI + BT BS & 2 \\
\hline 7. & 7 & BD BI + BT BI & 1 \\
\hline 8. & 8 & BT BS + BT BI & 1 \\
\hline 9. & 9 & BT BI + BD BI & 2 \\
\hline 10. & 10. & BD BI + BT BS & 1 \\
\hline 11 & 11 & BT BS + BD BI & 3 \\
\hline 12 & 12 & BT BS + BT BS & 42 \\
\hline 13 & 13 & Pola Unik &
\end{tabular}

Berdasarkan tabulasi data di atas, interferensi komposisi dari BI ke dalam BS dalam abstrak berjumlah 42 kata majemuk. Kajiannya didasarkan kepada bentuk dasar (BD) BS digabungkan dengan BD BI, bentuk turunan (BT) BI ke dalam BT BS, atau BT BI ke dalam BT BS. Berikut contoh analisisnya.

\section{a. Pola $1 \boldsymbol{B D}+B D B I$}

Pola 1 merupakan interferensi komposis dari BI ke dalam BS yang dibentuk dari BD BI dan unsur kedua BD BI. Kata yang berpola 1 terdapat Sembilan data, di antaranya: (017) asal daya,(047) bidang pendidikan,(056) data primer, (057) data skunder, (058) daya beli, (059) daya tarik, (116) gairah kerja,(196) kerja sama, jeung (244) masa depan.

\section{Interferensi Morfologis Reduplikasi}

Interferensi Morfologis Reduplikasi berdasarkan interferensi dari satu bahasa ke dalam bahasa lain, dalam hal ini BI ke dalam BS, dilihat dari unsurnya diulang. Data interferensi dari unsur morfologis kata ulang atau proses reduplikasi dalam abstrak hanya terdapat dua kata. Hasil analisis data interferensi morfologis reduplikasi tergolong dwimurni (Rdm) dan dwireka(Rdr).

a. Pola 1: Rdm

Pola pertama merupakan interferensi morfologis reduplikasi dwimurni sebab dibentuk dengan cara menyebut dua kali bentuk dasarnya. Terlihat pada data berikut.

(156) kahumandeuar-kahumandeuar 
b. Pola 2: Rdr

Pola kadua merupakan interferensi morfologis reduplikasi dwireka karena dibentuk dengan cara menyebut dua kali bentuk dasarnya dengan mengubah bunyi vokal /a/ menjdi /i/. Seperti pada data berikut

(425) parubahan-parubihan

\section{Interferensi Morfologis Akronim}

Interferensi morfologis akronim berdasarkan interferensi dari satu bahasa ke dalam bahasa lain, dalam hal ini BI ke dalam BS pada aspek singkatan. Data interferensi dari unsur morfologis akronik dalam abstrak hanya terdapat satu kata. Seperti data berikut

(635) waskat

Kata waskat merupakan singkatan dari BI. Kata singkatannya adalah pengawasan melekat. Sedangkan proses penyingkatannya adalah pengekalan 3 huruf akhir asal (awas) yang selanjutnya huruf depanya dihilangkan dan pengekalan 3 huruf akhir kata dasar (lekat) dan selanjutnya huruf awalnya dihilangkan. Dengan demikian kata ini merupakan interferensi gramatikal secara morfologis.

\section{Interferensi Leksikosemantis}

Interferensi leksikosemantis dari BI ke dalam BS merupakan masuknya kata-kata BI yang dipakai dalam BS. Dari jumlah 643 data yang mengandung interferensi terdapat 505 data interferensi dalam bentuk leksikosemantis. Dari seluruh data interferensi leksikosemantis ada yang murni dari bahasa Indonesia, ada serapan baik dari bahasa asing maupun dari bahasa daerah ada pula interferensi rekaan.

\section{Leksikosemantis Murni}

Interferensi leksikosemantis murni merupakan kata-kata murni BI dalam abstrak skripsi, padahal dalam BS pun memiliki kata tersebut. Dari hasil data ditemukan 225 interferensi leksikosemantis murni BI. Berikut contoh data leksikosemantis murni
BI di antaranya angket, arti, artikel, bahasa, dan sumber daya.

Dari hasil analisis terlihat bahwa katakata BI pada abstrak di antaranya karena kurang dikuasainya kata-kata dalam bahasa Sunda. Hal ini dapat dilihat pada contoh berikut

(033) berlabuh

Yaser Arafat pamingpin PLO sarta anggotana pamustunganna berlabuh di Libanon (JHI/AAR/T13/D1/B7)

Pada kalimat (033) digunakan kata BI berlabuh, padahal dalam BS terdapat kata yang lebih tepat adalah balabuh. Kata berlabuh termasuk interferensi leksikosemantis murni

\section{Interferensi Leksikosemantis Serepan}

Interferensi leksikal serapan adalah interferensi yang dipakai kata-kata murni serepan baik dari BI, basa asing, atau basa daerah.Dari hasil analisis data terdapat 100 kata yang merupakan unsur serapan, 80 merupakan kata serapan bahasa asing murni, 17 bahasa campuran, serta 3 merupakan unsur serapan dari bahasa dialek dan bahasa daerah lain di Indonesia.

Contoh berikut merupakan interferensi leksikosematis serepan di antaranya accidental sample, activitas, analisis, dan analisis kredit

Dari hasil analisis data dapat dilihat bahwa kata-kata serapan masih digunakan dikarenakan belum dimilikinya kata-kata tersebut dalam atau dalam BS sudah ada namun belum dimasukkan dalam kamus, meskipun sudah biasa digunakan dalam BS oleh masyarakat. Interferensi leksikosematis unsur serapan dapat dilihat pada contoh berikut.

(064) deskriptif analisis Padika panalungtikan yang dipaké nya éta deskriptif analisis. 
Pada kalimat DI (064) digunakan istilah deskriptif analisis yang dalam BS belum ada kata sebagai penggantinya. Kata deskriptif analitis menunjukkan adanya interferensi leksikosemantis murni serapan.

\section{Interferensi Leksikosemantis Unsur Rekaan}

Interferensi leksikosemantis bentuk rekaan adalah adanya kesalahan dalam menggunakan kata BS yang tidak sesuai dengan pemakainnya, kesalahan dalam penerjemahan, serta kesalahan menerjemahkan afiks. Dari hasil analisis data ditemukan data sejumlah 179 interferensi leksikosemantis bentuk rekaan.

Berikut contoh interferensi leksikosemantis unsur rekaan di antaranya ameh, barobah, dan dewasa ieu. Berikut contoh interferensi leksikosemantis unsur rekaan yang salah dalam menerjemahkan.

(628) usik

PDAM nu usik di bidang jasa pangladén cai inum

(PDAM yang bergerak di bidang jasa pelayanan air minum)

Pada kalimat (628) kata usik merupakan terjemahan dari katabergerak dalam BI. Sacara leksikon arti bergerak adalah usik. Dalam tataran semantiknya kata usik kurang benar dalam penggunaanya, Karena dalam BS terdapat kata yang tepat penggunaannya adalah usahana atau gerakna.

\section{Interferensi Berdasrkan Relasi Semantis}

Pada penelitian dari hasil analisis data berdasarkan relasi semantis ditemukan data berjumlah 500 kata yang termasuk sinonim dan 5 kata yang tergolong homonim.

\section{SIMPULAN DAN SARAN}

Tingkat inteferensi morfologis dan leksikosemantis BI ke BS dalam abstrak skripsi menunjukkan bahwa interferensi leksikosemantis lebih tinggi dari pada interferensi morfologis.
Dari data di atas dapat terlihat bahwa mahasiswa yang memiliki tingkat interferensi antara $0-10 \%$ ada 16 orang $(52,5 \%), 10-$ $20 \%$ terdapat 21 orang ( $40 \%)$, sedengkan yang berada di atas $20 \%$ hanya $(7,5 \%)$. Tingkat interferensi rendah menunjukkan tingkat kemampuan menulis yang tinggi. Sebaliknya, bila tingkat interferensi tinggi berarti kemampuan menulisnya rendah.

Penelitian ini diharapkan bisa memberikan gambaran kepada semua pihak yang terlibat sehingga tata cara menulis abstrak skripsi yang meggunakan bahasa Sunda agar lebih memperhatikan dengan benar-benar aturan morfologis dan leksikosemantisnya. Hal ini untuk menghasilkan abstrak skripsi yang sesuai dengan kaidah-kaidah tata bahasa yang berlaku.

Untuk pihak lembaga, diharapkan memberi kebijakan bahwa dalam menulis abstrak bahasa Sunda diperlukan bimbingan dari pihak yang ahli dalam bahasa Sunda, lebih baik lagi seandainya ada mata kuliah atau pengayaan mengenai bahasa Sunda.

\section{PUSTAKA RUJUKAN}

Alwasilah, A.C. (1993). Sosiologi Bahasa. Bandung: Rineka Cipta

Chaer, A \& Agustina, L. (2010). Sosiolinguistik Perkenalan Awal. Jakarta: Rineka Cipta.

Huda, N. dkk. (1981). Interferensi Gramatikal Bahasa Madura terhadap Bahasa Indonesia Tulis Murid Kelas IV Sekolah Dasar Jawa Timur. Jakarta: Pusbang Depdikbud.

Kridalaksana, H. (1994). Kelas Kata dalam Bahasa Indonesia. Jakarta: Pustaka Utama.

Parera, J.D. (1997). Linguistik Edukasional (Metodologi Pembelajaran Bahasa, Analisis Kontrakstif Antarbahasa, Analisis Kesalahan Berbahasa). Jakarta: Erlangga.

Pateda, M. (2010). Semantik Leksikal. Jakarta: Rineka Cipta. 
Sudaryat, Y. (2007). Tata Bahasa Sunda Kiwari. Bandung: Yrama Widya.

Suwito (1985). Sosiolinguistik Pengantar Awal. Surakarta: Henary Offset.

Tarigan, H.G. \& Tarigan, D. (2011). Pengajaran Analisis Kesalahan Berbahasa. Bandung: Angkasa

\section{UCAPAN TERIMA KASIH}

Kepada semua pihak yang telah membantu penelitian ini penulis mengucapkan terima kasih. Tidak luput pula ucapan terima kasih dan penghargaan setinggi-tingginya penulis sampaikan kepada penyunting Jurnal Lokabasa yang telah memuat tulisan ini. 